\section{Commentary: Cerebral protection during aortic decannulation: Long run for a short slide?}

\author{
Derek Serna-Gallegos, MD, and Ibrahim Sultan, MD
}

Postcardiotomy extracorporeal membrane oxygenation (ECMO) carries with it a very high risk of morbidity and mortality. Although only $1 \%$ of patients undergoing surgery require postcardiotomy ECMO, the prevalence has increased in recent years. ${ }^{1,2}$ Efforts have been made to identify patients at risk for postcardiotomy ECMO to better understand this patient population and decrease the associated morbidity and mortality. Ideally, when needed, patients can be transitioned to peripheral venoarterial (VA) ECMO via femoral or axillary arterial cannulation before leaving the operating room to facilitate chest closure. When the transition is performed at the time of the index operation, there may be less risk of an embolic event, because the patient is likely systemically heparinized throughout the operation and at the time of transition. In a situation where the patient cannot be transitioned to peripheral ECMO with systemic heparinization, thrombus formation at the arterial cannula may occur and can serve as an agent for an embolic stroke at the time of central decannulation.

In this issue of the Journal, Ohira and colleagues ${ }^{3}$ present a strategy to address this risk of cerebral embolic stroke due to thrombus formation at the arterial cannulation site when transitioning from central to peripheral ECMO. ${ }^{3}$ Their strategy involves protecting the cerebral circulation from embolism by first sewing a graft onto the right axillary artery and initiating perfusion through the axillary artery, then clamping the brachiocephalic vessels and instituting unilateral

From the Division of Cardiac Surgery, Department of Cardiothoracic Surgery, University of Pittsburgh and Heart and Vascular Institute, University of Pittsburgh Medical Center, Pittsburgh, Pa.

Disclosures: I.S. has received institutional research funding from AtriCure and Medtronic. D.S.-G. reported no conflicts of interest.

The Journal policy requires editors and reviewers to disclose conflicts of interest and to decline handling or reviewing manuscripts for which they may have a conflict of interest. The editors and reviewers of this article have no conflicts of interest.

Received for publication Oct 1, 2020; revisions received Oct 1, 2020; accepted for publication Oct 9, 2020; available ahead of print Oct 15, 2020.

Address for reprints: Ibrahim Sultan, MD, Center for Thoracic Aortic Disease, Heart and Vascular Institute, University of Pittsburgh Medical Center, 5200 Centre Ave,

Suite 715, Pittsburgh, PA 15232 (E-mail: sultani@upmc.edu).

JTCVS Techniques 2020;4:195-6

2666-2507

Copyright (C) 2020 The Authors. Published by Elsevier Inc. on behalf of The American Association for Thoracic Surgery. This is an open access article under the CC BY-NCND license (http://creativecommons.org/licenses/by-nc-nd/4.0/).

https://doi.org/10.1016/j.xjtc.2020.10.008

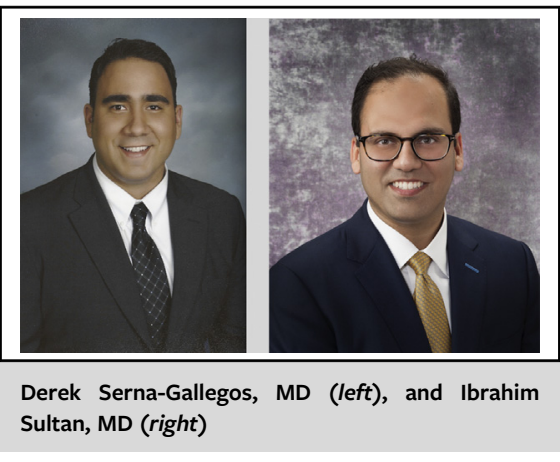

CENTRAL MESSAGE

The use of antegrade cerebral perfusion and sequential brachiocephalic clamping while transitioning patients from central to peripheral extracorporeal membrane oxygenation ECMO may lead to embolic events.

antegrade cerebral perfusion via the right carotid artery while the aortic cannula is removed and the aortic pursestring is tied. After the aortic cannula is removed, the innominate artery clamp is released and the flow is increased, allowing for back-bleeding of the cannulation site and ejection of any debris. The authors report that the duration of unilateral cerebral perfusion with the arch vessels clamped is usually less than 90 seconds.

This strategy has not been used in a significant number of patients and thus cannot be evaluated with any meaningful statistical approaches. The theoretical benefit of this strategy must be balanced against the theoretical risk of stroke due to brachiocephalic vessel manipulation and unilateral cerebral perfusion. This strategy must address the large variability across studies in the percentage of patients with a nonintact circle of Willis. Previous studies have shown a wide variation in the incidence of hypoplasia of the component arteries of the circle of Willis collateral system, ranging from $0.7 \%$ to $85.5 \%{ }^{4}$ For this strategy to be beneficial, the risk of embolic stroke from the arterial decannulation site must exceed the incidence of patients without an intact circle of Willis, which is very difficult to determine, as can be inferred from the large variation in the reported rate of intact cerebral collateral circulation.

The burden of stroke from cardiac surgery is not trivial, and this is increasingly worse in patients who require 
postcardiotomy ECMO. ${ }^{5}$ Although we applaud the authors' efforts to minimize the burden of stroke, this strategy itself may put the patient at risk for stroke because of the aforementioned reasons. In addition, this strategy disobeys the age-old edict of not performing more dissection than is necessary. Thankfully, few postcardiotomy patients require VA ECMO, and the number needed to treat to determine a difference likely will be rather large. Finally, recent data demonstrate a high rate of magnetic resonance imagingbased cerebral embolic lesions in virtually all patients undergoing antegrade cerebral perfusion albeit this was done for patients undergoing arch replacement which was not the case here. ${ }^{6}$ It will be important for surgeons to weigh the risks and benefits of this approach before adapting this as the default strategy for postcardiotomy ECMO.

\section{References}

1. Sultan I, Habertheuer A, Wallen T, Siki M, Szeto W, Bavaria JE, et al. The role of extracorporeal membrane oxygenator therapy in the setting of type A aortic dissection. J Card Surg. 2017;32:822-5.

2. Maxwell BG, Powers AJ, Sheikh AY, Lee PHU, Lobato RL, Wong JK. Resource use trends in extracorporeal membrane oxygenation in adults: an analysis of the Nationwide Inpatient Sample 1998-2009. J Thorac Cardiovasc Surg. 2014;148: 416-21.e1.

3. Ohira S, Spielvogel D, Lansman SL, Kai M. Unilateral antegrade cerebral perfusion using axillary venoarterial extracorporeal membrane oxygenation during central decannulation. J Thorac Cardiovasc Surg Tech. 2020;4:189-92.

4. Fawcett E, Blachford JV. The circle of Willis: an examination of 700 specimens. $J$ Anat Physiol. 1905;40(Pt 1):63.2-70.

5. Sultan I, Bianco V, Kilic A, Jovin T, Jadhav A, Jankowitz B, et al. Predictors and outcomes of ischemic stroke after cardiac surgery. Ann Thorac Surg. 2020;110: 448-56.

6. Leshnower BG, Rangaraju S, Allen JW, Stringer AY, Gleason TG, Chen EP. Deep hypothermia with retrograde cerebral perfusion versus moderate hypothermia with antegrade cerebral perfusion for arch surgery. Ann Thorac Surg. 2019;107:1104-10. 